\title{
Peptide Cotransmitter Release from Motorneuron B16 in Aplysia californica: Costorage, Corelease, and Functional Implications
}

\author{
Ferdinand S. Vilim, ${ }^{1}$ Elizabeth C. Cropper, ${ }^{1}$ David A. Price, ${ }^{2}$ Irving Kupfermann, ${ }^{3}$ and Klaudiusz R. Weiss ${ }^{1}$ \\ ${ }^{1}$ Department of Physiology and Biophysics, Mount Sinai School of Medicine, New York, New York 10029, ${ }^{2} \mathrm{C}$. V. Whitney \\ Laboratory, University of Florida, St. Augustine, Florida 32086, and ${ }^{3}$ Center for Neurobiology and Behavior, College of \\ Physicians and Surgeons of Columbia University, New York, New York 10032
}

Many neurons contain multiple peptide cotransmitters in addition to their classical transmitters. We are using the accessory radula closer neuromuscular system of Aplysia, which participates in feeding in these animals, to define the possible consequences of multiple modulators converging on single targets. How these modulators are released onto their targets is of critical importance in understanding the outcomes of their modulatory actions and their physiological role. Here we provide direct evidence that the partially antagonistic families of modulatory peptides, the myomodulins and buccalins, synthesized by motorneuron B16 are costored and coreleased in fixed ratios. We show that this release is calcium-dependent and independent of muscle contraction. Furthermore, we show that peptide release is initiated at the low end of the physiological range of motorneuron firing frequency and that it increases with increasing motorneuron firing frequency. The coordination of peptide release with the normal operating range of a neuron may be a general phenomenon and suggests that the release of peptide cotransmitters may exhibit similar types of regulation and plasticity as have been observed for classical transmitters. Stimulation paradigms that increase muscle contraction amplitude or frequency also increase peptide release from motor neuron B16. The net effect of the modulatory peptide cotransmitters released from motorneuron B16 would be to increase relaxation rate and therefore allow more frequent and/or larger contractions to occur without increased resistance to antagonist muscles. The end result of this modulation could be to maximize the efficiency of feeding.

Key words: Aplysia; neuropeptide; cotransmitter; buccalin; myomodulin; immunolocalization; RIA; release; motorneuron
Neuropeptides, the most diverse class of signaling molecules in the nervous system, are often hypothesized to function as cotransmitters. However, despite their pervasiveness and undoubtedly important function in the nervous system, most neuropeptides retain the status of putative rather than established cotransmitters. Furthermore, many neurons contain multiple, functionally distinct peptides (Kupfermann, 1991; Iversen, 1995). Without detailed knowledge of the actions and release parameters of peptide cotransmitters, it is virtually impossible to determine their physiological function. It has been suggested that the task of understanding the functional role of neuropeptides may be facilitated by studying relatively simple preparations where the biological context is well understood (Iversen, 1995).

One preparation in which both the biological context and the nature of the primary transmitters and cotransmitters have been extensively studied is the accessory radula closer (ARC) muscle of Aplysia (Weiss et al., 1992). This muscle is innervated by two cholinergic motorneurons, B15 and B16. Each of these motor neurons also contains multiple neuropeptides, which are members of two distinct neuropeptide families that have partially antagonistic effects on muscle. The cellular mechanisms of action of

Received Oct. 11, 1999; revised Dec. 10, 1999; accepted Dec. 20, 1999.

This work was supported by the National Institute of Mental Health through Grants MH36730 and K05MH01427 to K.R.W. and MH01267 and MH51393 to E.C.C. Aplysia californica were partially provided by the National Resource for Aplysia at the University of Miami under National Institutes of Health National Center for Research Resources Grant RR10294. We thank Dr. Paul Church for critical reading of this manuscript.

Correspondence should be addressed to F. S. Vilim, Box 1218, Department of Physiology and Biophysics, Mount Sinai School of Medicine, New York, NY 10029. E-mail: vilim@inka.mssm.edu.

Copyright (c) 2000 Society for Neuroscience $\quad 0270-6474 / 00 / 202036-07 \$ 15.00 / 0$ acetylcholine, the primary transmitter, and of the neuropeptides have been well characterized. Furthermore, because the firing of motorneurons in freely behaving animals has been characterized (Cropper et al., 1990b), previous work provides an excellent background for more advanced studies of peptide release and peptide action in this system.

Motorneuron B15 contains the SCPs and buccalins (BUCs), whereas motorneuron B16 contains the myomodulins (MMs) and BUCs (Weiss et al., 1992). The SCPs and MMs act postsynaptically to increase contraction amplitude and relaxation rate, whereas the BUCs depress contraction amplitude by reducing $\mathrm{ACh}$ release. How these motorneurons release these peptides critically affects the interpretation of the biological function of the neuromuscular system (Brezina et al., 1996). In a recent series of studies, we conclusively demonstrated that neuron B15 coreleases SCPs and BUCs in a fixed ratio and that release occurs within the normal range of firing frequencies of B15 (Vilim et al., 1996a,b). However, motorneuron B16 contains a different set of partially antagonistic peptide families and exhibits a different range of firing frequencies (Cropper et al., 1990b). Because motorneuron B16 is coactive with motorneuron B15, it is also important to determine the release parameters for the modulators contained in B16 if an understanding of their role in the functioning of the system is to be achieved.

In the present study we sought to achieve three goals. First, to measure the release of MMs from motorneuron B16. This is of particular importance because despite the presence of MMs and related peptides in a number of systems of a variety of species (Brezina et al., 1995; Kellett et al., 1996; Greenberg et al., 1997; Wang et al., 1998), no direct evidence exists for their release. 
Second, we sought to determine if the MMs and BUCs are released in a fixed or a variable ratio from motorneuron B16. Third, we sought to determine whether or not release of the peptides is coordinated with the normal range of firing frequencies for B16.

\section{MATERIALS AND METHODS}

Animals. Specimens of Aplysia californica were maintained at $14-16^{\circ} \mathrm{C}$ on a $12 \mathrm{hr}$ light/dark cycle and fed every $3 \mathrm{~d}$. Before dissection animals were injected with isotonic $\mathrm{MgCl}_{2}(25-50 \%$ body wt).

Antibodies. The rabbit antibody to buccalin used for immunocytochemistry and RIA was raised against BUCa coupled to bovine serum albumin (BSA), as has been described previously (Miller et al., 1991, 1992; Vilim et al., 1996a,b). The rat antibody to MMa used for immunocytochemistry was raised against MMa coupled to bovine thyroglobulin (BTG). The rabbit antibody to MMc described previously (Miller et al., 1991) was not sufficiently sensitive for RIA. Consequently, a new antibody was made. Because we had previously obtained the best sensitivity with BSA-coupled antigens, we decided to make two new antibodies, one against MMa coupled to BSA and the other against MMa coupled to BTG. RIA tests of these antibodies indicated that the titer (and sensitivity) of the BSA-coupled antigen kept increasing with additional boosts, whereas the titer of the BTG-coupled antigen leveled off after about the third boost. In the end, the tenth and final bleed of the BSA-coupled MMa antigen had the best sensitivity and was used in all the release experiments. The peptides were coupled to the carrier protein with 1-ethyl-3-(3-dimethylaminopropyl)carbodiimide (EDC). All the antibodies were prepared by BABCO (Richmond, CA), and the peptides were synthesized by Applied Biosystems (Foster City, CA).

Immunocytochemistry. Immunocytochemistry was performed as previously described (Vilim et al., 1996a). Tissues were fixed in freshly prepared fixative (4\% paraformaldehyde, $0.2 \%$ picric acid, $25 \%$ sucrose, and $0.1 \mathrm{M} \mathrm{NaH}_{2} \mathrm{PO}_{4}, \mathrm{pH} \mathrm{7.6)}$ for either $3 \mathrm{hr}$ at room temperature (RT) or overnight at $4^{\circ} \mathrm{C}$. After washes with PBS to remove the fixative, ganglia from larger animals were desheathed to expose the neurons whereas ganglia from smaller animals $(10-15 \mathrm{gm})$ were processed without desheathing. All subsequent incubations were done at RT with rocking. Tissue was permeabilized and blocked by overnight incubation in blocking buffer (BB: 10\% normal donkey serum, 2\% Triton X-100, 1\% BSA, $154 \mathrm{~mm} \mathrm{NaCl}, 10 \mathrm{~mm} \mathrm{Na}_{2} \mathrm{HPO}_{4}, 50 \mathrm{~mm}$ EDTA, and $0.01 \%$ thimerosal, $\mathrm{pH}$ 7.4). The primary antibody was diluted 1:250 in BB and incubated with the tissue for 4-7 d. The tissue was then washed twice a day for 2-3 $\mathrm{d}$ with washing buffer (WB: $2 \%$ Triton $\mathrm{X}-100,1 \% \mathrm{BSA}, 154 \mathrm{~mm} \mathrm{NaCl}$, $10 \mathrm{~mm} \mathrm{Na} 2 \mathrm{HPO}_{4}, 50 \mathrm{~mm}$ EDTA, and $0.01 \%$ thimerosal, pH 7.4). After the washes, the tissue was incubated with 1:500 dilution of secondary antibody (lissamine-rhodamine donkey anti-rat; Jackson ImmunoResearch, West Grove, PA) for 2-3 d. The tissue was then washed twice with WB for $1 \mathrm{~d}$ and four times with storage buffer (SB: $1 \%$ BSA, $154 \mathrm{~mm}$ $\mathrm{NaCl}, 10 \mathrm{~mm} \mathrm{Na} \mathrm{HPO}_{4}, 50 \mathrm{~mm}$ EDTA, and $0.01 \%$ thimerosal, $\mathrm{pH} 7.4$ ) for $1 \mathrm{~d}$. The tissues were then stored at $4^{\circ} \mathrm{C}$ or viewed and photographed on a Nikon microscope equipped with epifluorescence.

EM immunocytochemistry. Procedures used for these experiments were adapted from those of others (Reed et al., 1988; Merighe et al., 1989), as has been described (Vilim et al., 1996a). Briefly, tissue was fixed (4\% glutaraldehyde, $10 \%$ sucrose, $11 \mathrm{~mm}$ magnesium chloride, and $0.2 \mathrm{M}$ Na HEPES, pH 7.6) for $3 \mathrm{hr}$ (RT), post-fixed with $1 \%$ osmium tetroxide in buffer at $4^{\circ} \mathrm{C}$ for $1 \mathrm{hr}$, and embedded in EMbed 812 (EM Sciences). Ultrathin sections were etched with saturated sodium metaperiodate, washed with TBS, then blocked with $8 \%$ normal goat serum in TBS for $1 \mathrm{hr}$. The sections were stained overnight with a 1:100 dilution of primary antibody, washed, then stained for $1 \mathrm{hr}$ in a 1:4 dilution of gold-labeled secondary antibody (Amersham, Arlington Heights, IL). The sections were lightly counterstained with uranyl acetate and lead citrate, then examined and photographed with a JEOL $100 \mathrm{CX}$ at $80 \mathrm{kV}$. Electron microscopy supplies and reagents were obtained from EMS (Fort Washington, PA).

Radioimmunoassays. Desaminotyrosinated MMa and BUCa were iodinated $\left({ }^{125} \mathrm{I}\right)$ using the chloramine $\mathrm{T}$ method. Iodinated stocks were repurified using reverse-phase HPLC and diluted in RIA buffer (154 mM $\mathrm{NaCl}, 10 \mathrm{~mm} \mathrm{Na} 2 \mathrm{HPO} 4,50 \mathrm{~mm}$ EDTA, $0.25 \mathrm{~mm}$ thimerosal, and $1 \%$ BSA, pH 7.5) to a final activity of $10,000-15,000 \mathrm{cpm} / 100 \mu \mathrm{l}$. Antibodies were diluted in RIA buffer so that $100 \mu \mathrm{l}$ bound $\sim 50 \%$ of the counts in $100 \mu \mathrm{l}$ of iodinated peptide trace (with a sample volume of $50 \mu \mathrm{l}$ ). The reaction was performed for $2-3 \mathrm{~d}$ at $4^{\circ} \mathrm{C}$ and terminated by addition of 2 $\mathrm{ml}$ of RIA charcoal (10 $\mathrm{mm} \mathrm{Na} \mathrm{Na}_{2} \mathrm{HPO} 4,0.25 \mathrm{~mm}$ thimerosal, $0.25 \%$ activated charcoal, $0.025 \% 70,000 \mathrm{kDa}$ dextran, $\mathrm{pH} 7.5)$. The samples were spun and the supernatant, containing the bound peptide, was decanted and counted in a gamma counter. Standard curves were generated using serial dilutions of peptide in $50 \mu \mathrm{l}$ of artificial sea water containing $1 \%$ BSA to prevent sticking. A spreadsheet program (Kaleidagraph 2.1) was used to plot the standard curves, to convert counts bound to femtomoles of peptide in the unknowns, and display the data as graphs. Because the RIAs are probably measuring the release of more than one peptide cotransmitter within a family (Price, 1990), the release of the family is referenced (i.e., $\mathrm{MM}=\mathrm{MMa}$, b, etc. and $\mathrm{BUC}=$ BUCa, b, etc.; Miller et al., 1993a,b). Because different preparations released differing amounts of peptide, the data were normalized to the average release for all the stimulation periods in a single experiment. The percentage of average release was calculated by adding all the released peptide detected in the experiment and dividing by the total number of stimulation periods. The release for each stimulation period was then divided by the average release for that experiment and multiplied by 100 . The normalized data were then combined for the same experimental conditions across different preparations, and statistical analysis was performed. A statistical analysis program (StatView 4.5) was

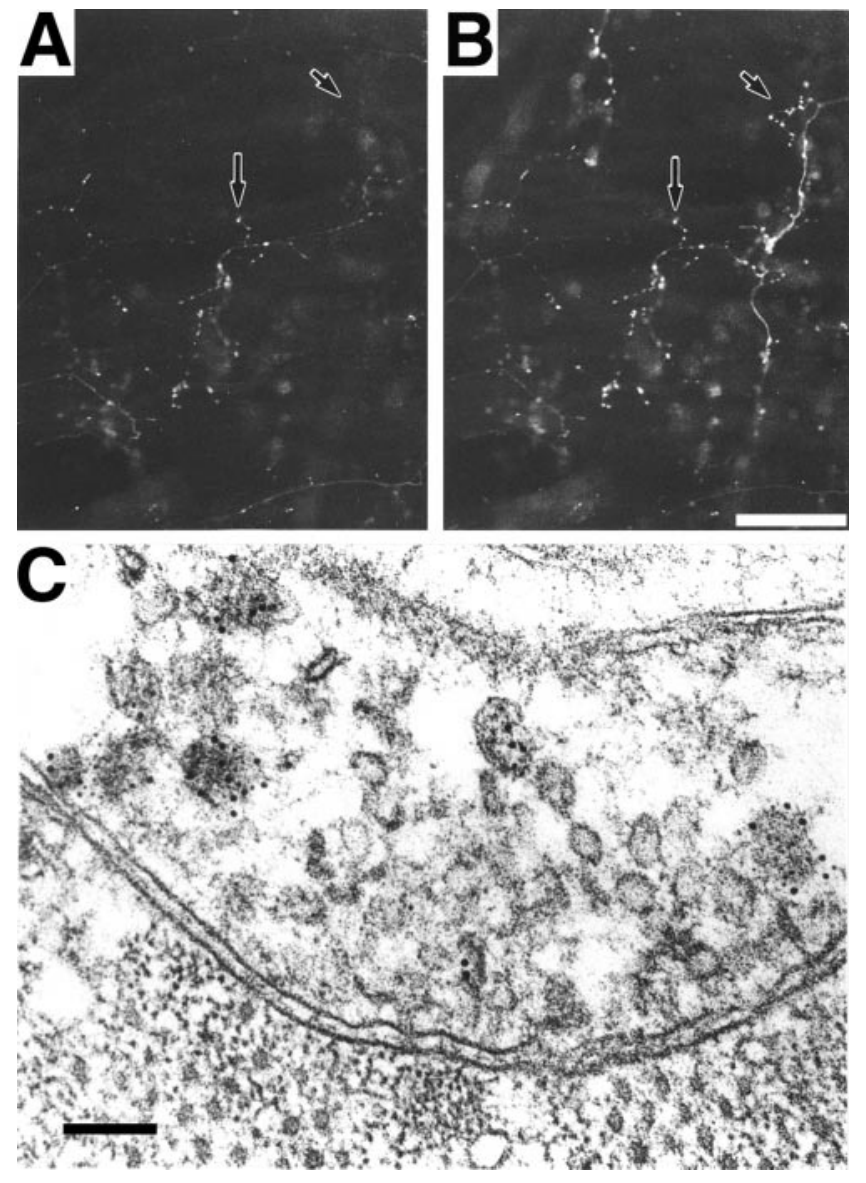

Figure 1. A, Myomodulin immunostaining in the ARC muscle using lissamine-rhodamine-conjugated donkey anti-rat secondary antibody. $B$, Buccalin immunostaining of the same field in the ARC muscle using fluorescein-labeled donkey anti-rabbit secondary antibody. Short arrows point to processes that stain for buccalin alone and correspond to B15 processes. Longer arrows point to processes that stain for both myomodulin and buccalin, corresponding to B16 processes. Scale bar, $100 \mu \mathrm{m}$ (applies to $A$ and $B$ ). $C$, Post-embedding immunogold dual labeling of BUC and MM in a B16 neuromuscular junction of the ARC. BUC is labeled with a rabbit antibody and a $5 \mathrm{~nm}$ gold-labeled secondary antibody. MM is labeled with a rat antibody and a $10 \mathrm{~nm}$ gold-labeled secondary antibody. Most of the DCVs are labeled with both small $(5 \mathrm{~nm})$ and large $(10 \mathrm{~nm})$ gold particles, indicating the presence of both BUCs and MMs in the same DCVs. Scale bar, $100 \mathrm{~nm}$. 
Figure 2. Effect of extracellular calcium and hexamethonium on peptide release from B16 in the ARC. A1, Results from a single experiment in which MM release is measured with and without normal calcium in the perfusate. Motorneuron B16 was stimulated during four 5 min periods (indicated by the black bars) with a physiologically relevant frequency and pattern ( $20 \mathrm{~Hz}$ for $3.5 \mathrm{sec}$ every $7 \mathrm{sec})$. A2, The average of four such experiments for each peptide. For each peptide, the mean \pm SE of four separate experiments is plotted at each calcium concentration. The results show that release of both peptides is dependent on extracellular calcium $(p<0.0001) . B 1$, Results from a single experiment in which BUC release is measured without and with $0.1 \mathrm{~mm}$ hexamethonium (which completely abolished the contraction of the muscle) in the perfusate. Motorneuron B16 was stimulated during four 5 min periods (indicated by the black bars) with a physiologically relevant frequency and pattern $(20 \mathrm{~Hz}$ for $3.5 \mathrm{sec}$ every $7 \mathrm{sec}) . B 2$, The mean $\pm \mathrm{SE}$ of the normalized release from four such experiments for each peptide. The results show that release of both peptides is not dependent on contraction of the muscle $(p>0.5)$.
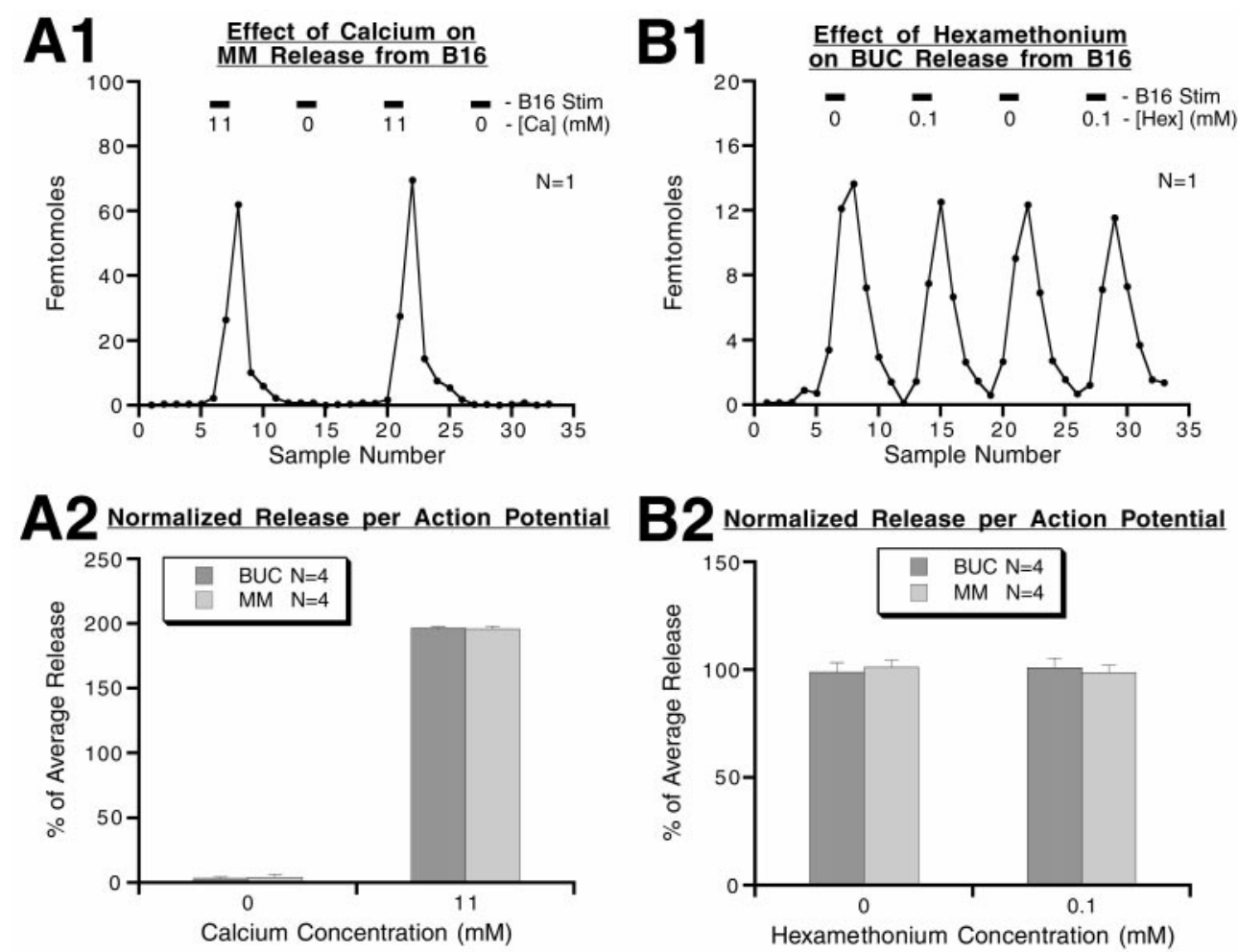

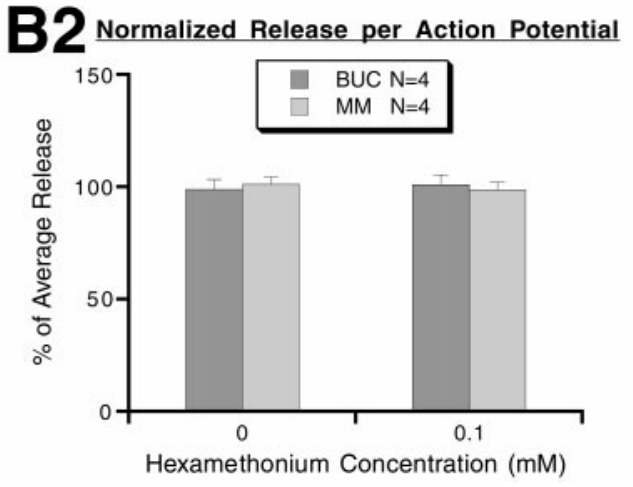

used to perform a within-subject repeated-measures ANOVA on relevant data to assess the overall level of statistical significance. Individual comparisons were performed using paired $t$ tests.

Release preparation. The ARC buccal ganglion preparation was isolated as described elsewhere (Vilim et al., 1996a). Briefly, the buccal ganglion was pinned in a dish containing $25 \%$ isotonic $\mathrm{MgCl}_{2}$ to prevent spontaneous activity, and the nerve was passed through a slit in the side of the dish. The ARC was suspended outside the dish and encased with a combination of silicone grease (Dow Corning, Corning, NY) and parafilm. The ARC was perfused through an artery, and the perfusate was collected (drops, every $2.5 \mathrm{~min}$ ) directly into the RIA tubes. The motorneuron was impaled with two independent glass microelectrodes, one for recording voltage, and one for injecting current. The temperature of the ARC was maintained at $15 \pm 0.5^{\circ} \mathrm{C}$ by cooling the room with an air conditioner. For the experiments examining the effects of calcium and hexamethonium on peptide release, the agents were introduced into the ARC via the perfusion line. The perfusing solutions were exchanged simply by turning a peristaltic pump off and transferring the perfusion inlet into another solution, and turning the perfusion line on again. This method maintained a constant rate of perfusion for the different perfusing solutions, and the small dead volume $(<100 \mu \mathrm{l})$ enabled fairly rapid $(<5 \mathrm{~min})$ exchange of solutions. All reagents were obtained from Sigma (St. Louis, MO) except where otherwise noted.

\section{RESULTS}

The accessory radula closer muscle is innervated by two cholinergic motorneurons, B15 and B16 (Cohen et al., 1978). Motorneuron B15 contains SCPs (Cropper et al., 1987a), motorneuron B16 contains MMs (Cropper et al., 1987b, 1991), and both contain BUCs (Cropper et al., 1988; Cropper et al., 1990a; Vilim et al., 1994). This is illustrated by the LM immunocytochemistry in Figure 1. Here you can see processes immunostaining for buccalin and myomodulin that are indicative of B16 processes. (In addition, there are processes immunostaining for buccalin but not myomodulin that are indicative of B15 processes.) To subcellularly localize the B16 peptides, we performed EM immunocytochemistry. We found that MM is present in dense core vesicles (DCVs), which had not been shown. In fact we found that vesicles that are myomodulin-immunoreactive are also buccalin- immunoreactive. Data from three preparations with 13 terminals containing a total of 122 DCVs showed that $97(79.5 \%)$ were costained with myomodulin and buccalin. In contrast, 10 B15 terminals from the same sections contained 220 DCVs staining for buccalin, and only four of those vesicles had gold particles corresponding to myomodulin staining. These results demonstrate that the overall background levels were low and that the immunostaining is specific. Thus, LM and EM evidence indicates that the BUCs and MMs are not differentially packaged and targeted. However, this evidence cannot determine whether the relative amounts of MMs and BUCs are fixed in all DCVs.

To approach this issue we first sought to determine whether peptides were released from B16 constitutively or in an activitydependent manner. Both peptides were in fact released in a calcium-dependent manner when B16 was stimulated (Fig. 2A) $(n=4)$ (intraburst firing frequency, $20 \mathrm{~Hz}$; burst duration, $3.5 \mathrm{sec}$; interburst interval, $3.5 \mathrm{sec}$ ). Because low calcium solutions not only block release but also prevent muscle contractions, the above results could be obtained if the peptides were constitutively released and squeezed into the eluate by muscle contractions. We therefore used hexamethonium, a cholinergic antagonist that blocks muscle contractions but does not inhibit the release process (Vilim et al., 1996a). Under these conditions we again observed that the release of both peptides depended on motorneuron firing (Fig. $2 B)(n=4)$ (firing rate, $20 \mathrm{~Hz}$; burst duration, 3.5 sec; interburst interval, $3.5 \mathrm{sec})$. Because the motorneuron in these experiments was stimulated within its normal firing rate and pattern, this experiment indicates that peptide release is physiologically relevant. Furthermore, it is the first direct demonstration that MMs are released in any system.

We next wanted to define whether or not the ratio was fixed during release. To accomplish this, we stimulated for a longer period of time and analyzed alternate samples for MM or BUC content. By comparing the kinetics of BUC and MM release, we 

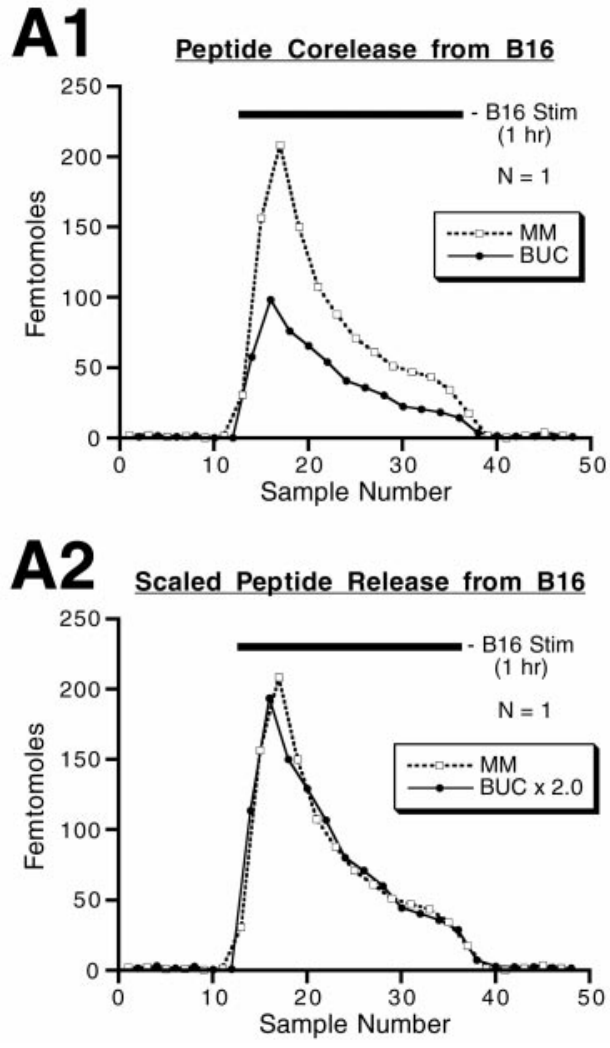
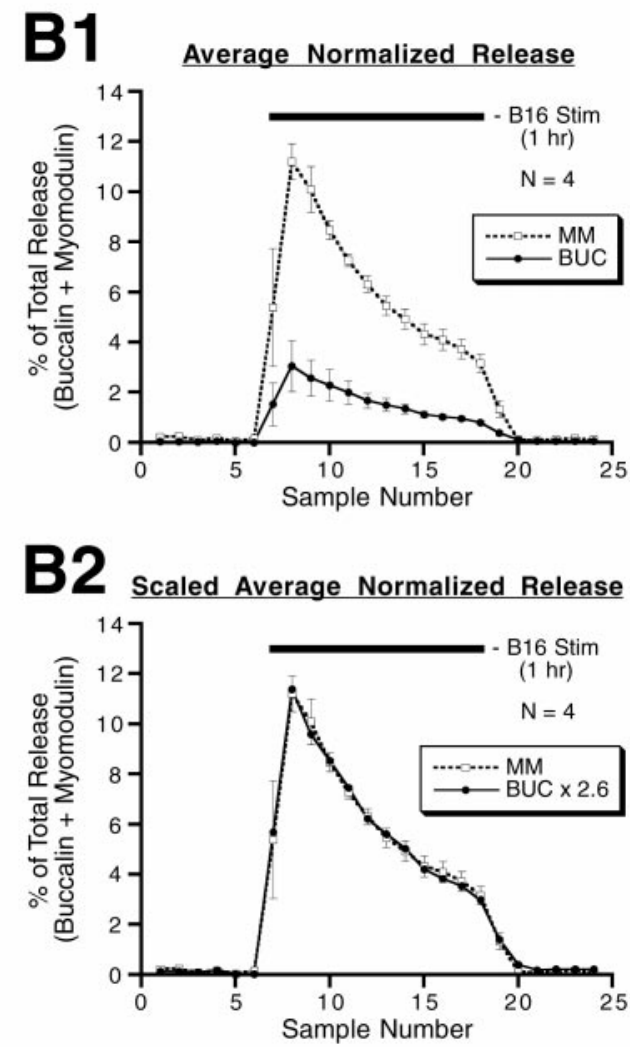

Figure 3. Corelease of MMs and BUCs within the ARC in response to stimulation of motorneuron B16. During the $1 \mathrm{hr}$ period indicated by the bar, the neuron was fired at $20 \mathrm{~Hz}$ for $3.5 \mathrm{sec}$ every $7 \mathrm{sec}$, which is within the physiological range of B16 firing. Samples of ARC perfusate were collected every $2.5 \mathrm{~min}$ and analyzed by radioimmunoassay for their peptide content. Alternate samples were analyzed for their MM or BUC content. A1, MM and BUC release in a single experiment. $A 2$, Same as $A 1$ except that BUC was scaled so those total amounts released were equal for both $\mathrm{MM}$ and BUC, enabling a more direct comparison of their profiles. B1, MM and BUC release from four experiments was expressed as a percentage of the total amount of peptide $(\mathrm{MM}+\mathrm{BUC})$ released in the experiment, and the percentages were averaged for each 5 min (2 sample) period. B2, Same as $B 1$, except that BUC was scaled so that total percentages were equal for both MM and BUC, enabling a more direct comparison of their profiles. The ratio of MM and BUC remains constant even though the absolute peptide content of the samples varies considerably over the course of B16 stimulation. can determine if the ratio is fixed or not. When the motorneuron is stimulated at a constant frequency over time, even though the amount of peptides released changes, the ratio of the two peptides remains constant (Fig. 3) $(n=4)$ (firing rate, $20 \mathrm{~Hz}$; burst duration, $3.5 \mathrm{sec}$; interburst interval, $3.5 \mathrm{sec}$; total period of stimulation, $1 \mathrm{hr}$ ). This observation was confirmed by further experiments in which we manipulated the parameters of motorneuron stimulation and found that although the total amount of peptides released from B16 changed as a function of the parameters of stimulation, the ratio of the two peptides remained constant (see below).

Because the two peptides are released together and they are released in a constant ratio, the functional role of corelease in this system requires that the action of the two peptides be conceptualized jointly. As indicated before, the joint action of these two peptides is to preferentially accelerate the relaxation rate and thus to shorten the duration of the relaxation of the contraction. Accelerated relaxation rate promotes unopposed action of antagonistic muscles, especially when muscle contractions occur frequently and/or are large (Fig. 4A1,B1). We therefore investigated the relationship between peptide release and those parameters of motorneuron stimulation that produce frequent or large contractions. Different frequencies of muscle contractions were produced by changing the interburst interval of motorneuron firing while maintaining a constant intraburst frequency and burst duration. All of these parameters used were within the physiological range of motorneuron firing, i.e., the intraburst firing frequency was 20 $\mathrm{Hz}$, the burst duration was $3.5 \mathrm{sec}$, and interburst intervals were 3.5, 5.0, and $7.5 \mathrm{sec}$ (Cropper et al., 1990b). Data from an individual experiment in which we measured the release of buccalin are shown in Figure $4 A 2$. We observed that indeed peptide release was greater when a motorneuron was stimulated to pro- duce more frequent contractions. Because there are more action potentials per unit of time when the interburst interval is shorter, we expressed peptide release as femtomoles per action potential. The plot of these data is shown in Figure $4 A 3$, and it indicates that indeed release per action potential increased as the frequency of contractions increased $(n=4)$. The second set of conditions under which faster relaxation rate is advantageous occurs when muscle contractions are large (Fig. 4B1). We varied the size of muscle contractions by changing the intraburst frequencies while maintaining a constant burst duration and interburst interval. Again all of these parameters were maintained within the physiological range (Cropper et al., 1990b), i.e., intraburst firing frequencies were 10,15 , and $20 \mathrm{~Hz}$, the burst duration was $3.5 \mathrm{sec}$, and the interburst interval was $3.5 \mathrm{sec}$. We found that indeed peptide release was largest when motorneurons were stimulated at frequencies that produced large contractions $(n=$ 4) (Fig. 4B2,B3). Importantly, in experiments in which we varied either the interburst interval or the intraburst frequency, peptide release occurred not only at the high end but also at the low end of our stimulation parameters. These parameters were selected to mimic the range of motorneuron activity recorded in freely behaving animals. Larger amounts of peptides were released under conditions that produced large or frequent contractions-conditions in which appropriate shortening of the relaxation has advantageous behavioral consequences.

\section{DISCUSSION}

Our results provide direct evidence that the BUCs and MMs are costored and coreleased from motorneuron B16 terminals in the ARC muscle. This release is calcium-dependent and contractionindependent, demonstrating that it is not artifactual. In addition, several observations suggest that the amounts of peptides that are 
Figure 4. Effect of increasing either contraction frequency or amplitude on peptide release from motorneuron B16. A1, Hypothetical consequences of increased rate of feeding with no concomitant alteration of muscle properties. The closer is not sufficiently relaxed and opposes the contractions of opener muscles. Consequently, the radula does not open, and functional feeding is compromised. When the relaxation rate of the closer muscle is increased, functional feeding can be restored. $A 2$, Results from a single experiment in which BUC release is measured at different interburst intervals, simulating changes in the rate of feeding, whereas the intraburst frequency $(20 \mathrm{~Hz})$ and the duration of bursts $(3.5 \mathrm{sec})$ are kept constant. The duration of stimulation in this type of experiment was $5 \mathrm{~min}$. The physiological range of interburst intervals for B16 varies from 3.5 to $10 \mathrm{sec}$ (or more) (Cropper et al., 1990b). BUC release decreases as the interval between bursts increases. A3, Peptide release is normalized to the total release during an experiment and for the total number of action potentials delivered in each condition. The results from four separate experiments for each peptide were averaged and plotted $( \pm \mathrm{SE})$ for each of the three interburst intervals. There is a statistically significant (BUC: $F=23.13 ; \mathrm{df}=2,6 ; p<0.002 \mathrm{MM}: F=$ 25.1 ; $\mathrm{df}=2,6 ; p<0.002)$ inverse relationship between peptide released per action potential and the duration between bursts. The fact that this relationship is nearly identical for the two peptides indicates that they are released at a fixed ratio. B1, Hypothetical consequences of increased contraction amplitude of the radula closer with no concomitant alteration of muscle properties. The closer is not sufficiently relaxed and opposes the contractions of opener muscles. Consequently, the radula does not open, and functional feeding is compromised. As in $A 1$, when the relaxation rate of the closer muscle is increased, functional feeding can be restored. B2, Results from a single experiment in which MM release is measured at three different intraburst frequencies, which produce contractions of differing amplitudes, while the duration of bursts (3.5 sec) and the interburst interval $(3.5 \mathrm{sec})$ are kept constant. The physiological range of firing frequencies for B16 varies between $10-20 \mathrm{~Hz}(\mathrm{Cropper}$ et al., $1990 \mathrm{~b})$. The duration of stimulation in this type of experiment was $5 \mathrm{~min}$. MM release is lower at the lower intraburst frequencies. B3, Normalized release per action potential at each of the three intraburst frequencies corrected to give the release per action potential. The results from four separate experiments for each peptide were averaged and plotted $( \pm \mathrm{SE})$ for each of the three intraburst frequencies of stimulation. There is a statistically significant $(\mathrm{BUC}$ : $F=47.36 ; \mathrm{df}=2,6 ; p<0.0005 ; \mathrm{MM}: F=126.78$; df = 2,6; $p<0.0001)$ increase of peptide released per action potential and as the frequency of action potentials increases. The fact that this relationship is nearly identical for the two peptides also indicates that they are released at a fixed ratio.

recovered and measured are a good reflection of the amounts released. Specifically, we are measuring the release of two different peptide families, and peptides from each of these families differ in their length and chemical structure. Despite these differences, the myomodulins and buccalins are recovered in constant ratios under high- and low-release conditions. Furthermore, despite the fact that individual preparations differed in the absolute amounts of peptides detected, the error bars of the combined normalized data from several preparations are all very small.

We demonstrate that peptide cotransmitter release from B16 increases in response to changes in firing patterns that result in contraction amplitude increases or decreases in the interval between contractions. Furthermore, we show that the peptide release is initiated at the low end of the physiological range of B16 firing frequency and then increases with increasing B16 firing frequency in the range recorded in vivo during feeding. Previously, we reported (Vilim et al., 1996b) that release of SCPs and BUCs from motorneuron B15 is coordinated with the range of firing frequencies observed in vivo when the animal feeds. How- ever, Cropper et al. (1990b) reported that the range of firing frequencies for B15 and B16 are somewhat different $(7-12 \mathrm{~Hz}$ for B15 and 10-20 Hz for B16). In Figure 5 we compare the release per spike from B15 and B16 as a function of the overall average frequency of motorneuron firing. It is clear that the release as a function of frequency is different for the two motorneurons, but increases for both as the frequency increases (above a certain threshold frequency, which appears to be different for the two neurons). Release of SCPs from neurons B1 and B2 in culture suggests that release from these neurons also appear to be coordinated with their in vivo firing (Whim and Lloyd, 1994). However, these neurons fire single action potentials in vivo (Lloyd et al., 1988) and also release peptide in response to single action potentials. These results support the general conclusion that neuropeptide release properties appear to be neuron-specific (as opposed to peptide-specific). Moreover, as hypothesized (e.g., Vilim et al., 1996a,b) peptide cotransmitter release is coordinated with the normal range of firing frequencies for neurons in Aplysia, and probably in other species as well. This is a more attractive 

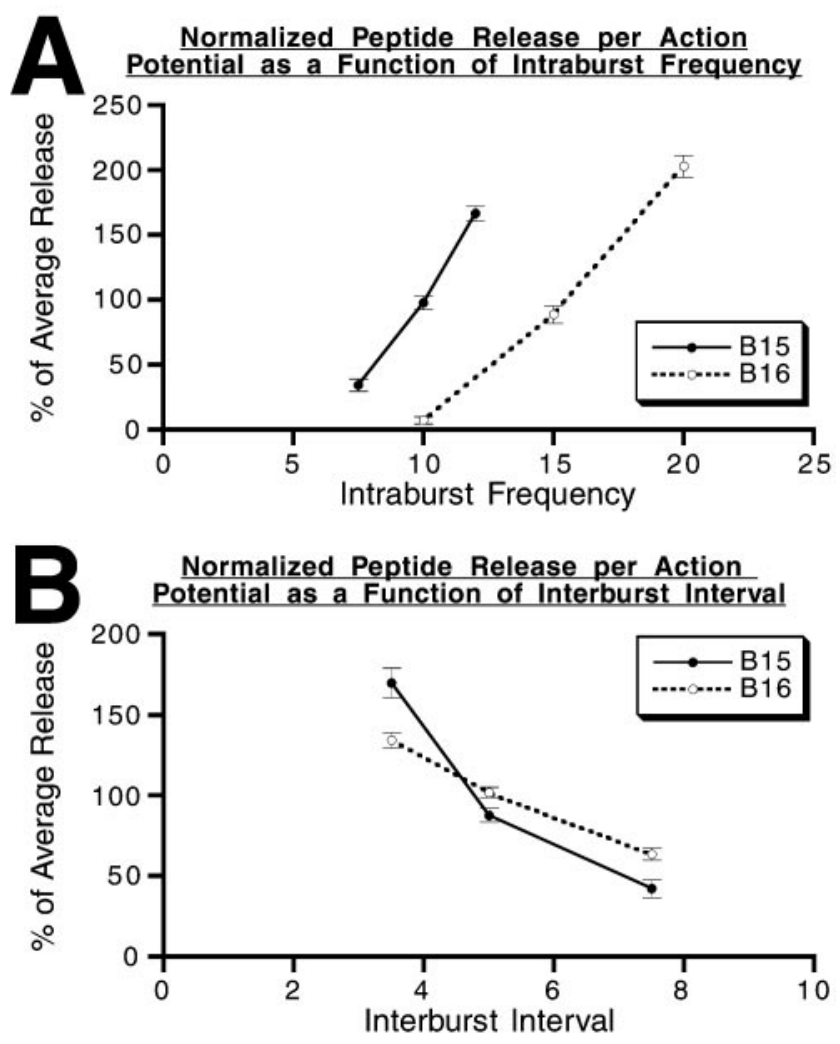

Figure 5. Comparison of the peptide release per action potential from motorneurons B15 and B16 as a function of intraburst frequency and interburst interval. $A$, Normalized release per action potential at each of the three intraburst frequencies corrected to give the release per action potential. Burst duration $(3.5 \mathrm{sec})$ and interburst interval $(3.5 \mathrm{sec})$ were identical in all experiments. The results from eight separate experiments for each motorneuron were averaged and plotted $( \pm \mathrm{SE})$ at three different intraburst frequencies of stimulation. The physiological range of firing frequencies for $\mathrm{B} 15$ varies between 7.5 and $12 \mathrm{~Hz}$, and $\mathrm{B} 16$ varies between 10 and $20 \mathrm{~Hz}$. Peptide release appears to be coordinated with the normal operating range of frequencies of each motorneuron. $B$, Normalized release per action potential at each of the three interburst intervals corrected to give the release per action potential. Burst duration $(3.5 \mathrm{sec})$ and intraburst frequencies $(12 \mathrm{~Hz}$ for $\mathrm{B} 15,20 \mathrm{~Hz}$ for B16) were identical in all experiments. The results from eight separate experiments for each motorneuron was averaged and plotted $( \pm$ SE) at three interburst intervals of stimulation $(3.5,5$, and $7 \mathrm{sec})$. The data for B15 have been described previously (Vilim et al., 1996b). The data for B16 were recalculated from Figure 4.

model of peptide release than one that postulates that peptide release only occurs at high frequencies (Hökfelt, 1991) because it allows for greater flexibility in output.

The peptide cotransmitters present in motorneuron B15 and B16 produce dose-dependent responses when applied exogenously to the preparation (Weiss et al., 1992; Brezina et al., 1995, 1996). They do not operate in an all or none manner. The peptide cotransmitters from these motorneurons are also released in a frequency-dependent rather than in an all or none manner within the normal range of firing frequencies for these two motorneurons. Furthermore, the release also changes gradually in response to changes in the interval between bursts or contractions (Fig. 5). Thus, the peptide cotransmitters in this system can alter the characteristics of muscle contractions, amplitude and relaxation rate, in a motorneuron firing-dependent manner. This can allow the coordination of the amplitude and relaxation rate of the muscle contractions to maximize the efficiency of the output of the system (Weiss et al., 1992). By altering the relaxation rate in response to the changing contraction amplitude and interval, inappropriate actions of antagonist muscles can be minimized, and the proper force can be maintained throughout a given phase of the cycle. This could be a built-in mechanism to adjust the response characteristics of the muscle to a wide range of amplitude and interval combinations.

The ARC is a nonspiking muscle in which the contraction amplitude is a function of the amount of ACh released (Cohen et al., 1978). Thus, release of classical transmitter correlates with contraction amplitude that in turn correlates with peptide cotransmitter release. In addition, release of ACh appears to be frequency-dependent (Lloyd and Church, 1994) as is peptide cotransmitter release. Hence, peptide cotransmitter and classical transmitter release appear to be functionally coupled in this system. Therefore, it is likely that there are key shared mechanisms for the release of classical and peptide cotransmitters. For example, both release processes are calcium-dependent. The calcium requirements for peptide and classical transmitter release, however, are different (Verhage et al., 1991; Llinas et al., 1992; Peng and Zucker, 1993), and the two can be differentially released (Matteoli et al., 1988), so some important differences in their mechanisms of release must exist.

In summary, our findings have several general implications for the understanding of peptidergic cotransmission. Peptide cotransmitters have been suggested to function as amplifiers of the actions of conventional transmitters, being released only at very high levels of neural firing (Hökfelt, 1991; Kupfermann, 1991). In many ways our findings are not consistent with this view and instead support the suggestions we have reached in our studies of peptide release from motorneuron B15 (Vilim et al., 1996a,b). Thus, our findings demonstrate that activity-dependent release of two modulatory peptide cotransmitters occurs throughout the normal firing range of a neuron, and although release becomes larger as the frequency of motorneuron firing increases, the release does not require extreme conditions in this system. Second, in this system the actions of the two peptides on the size of muscle contractions, the parameter regulated by the primary transmitter, tend to cancel each other and therefore the actions of these peptides are not easily conceptualized as simply amplifying the actions of the primary transmitter. Instead, the effect that emerges from the joint effect of these peptides is to modify the relaxation rate of contraction, an action that is not regulated by the primary transmitter. In view of the differences in the information transmitted by peptide cotransmitters and primary transmitters, these two classes of molecules are best conceptualized as constituting parallel but functionally distinct pathways of information transmission. Third, we found that peptides were preferentially released when motorneurons were stimulated to produce strong and frequent contractions, conditions that prevent full relaxation of the muscle before its antagonist muscle begins to contract. An incompletely relaxed muscle offers resistance to its antagonist, which may result in a disruption of the functional integrity of behavior. Furthermore, at higher rates of contraction a slow relaxation rate can result in inefficient stepwise summation and resultant tonic contractions. Because the amount of peptides that are released is an automatic consequence of the firing pattern of the motorneuron that produces the contraction, this arrangement obviates the need for complex sensory functions that would monitor on-line the state of muscle contraction to alter its rate of relaxation by engaging other neuronal input to the muscle. In more general terms, the use of peptide cotransmitters appears to 
be a simple and elegant way to automatically modify the characteristics of the response to the primary transmitter without the added computational complexity that would result from the incorporation of additional neuronal elements.

\section{REFERENCES}

Brezina V, Bank B, Cropper EC, Rosen S, Vilim FS, Kupfermann I, Weiss KR (1995) Nine members of the myomodulin family of peptide cotransmitters at the B16-ARC neuromuscular junction of Aplysia. J Neurophysiol 74:54-72.

Brezina V, Orekhova IV, Weiss KR (1996) Functional uncoupling of linked neurotransmitter effects by combinatorial convergence. Science 273:806-810.

Cohen JL, Weiss KR, Kupfermann I (1978) Motor control of buccal muscles in Aplysia. J Neurophysiol 41:157-180.

Cropper EC, Lloyd PE, Reed W, Tenenbaum R, Kupfermann I, Weiss KR (1987a) Multiple neuropeptides in cholinergic motor neurons of Aplysia: evidence for modulation intrinsic to the motor circuit. Proc Natl Acad Sci USA 84:3486-3490.

Cropper EC, Tenenbaum R, Kolks MAG, Kupfermann I, Weiss KR (1987b) Myomodulin: a bioactive neuropeptide present in an identified cholinergic buccal motor neuron of Aplysia. Proc Natl Acad Sci USA 84:5483-5486.

Cropper EC, Miller MW, Tenenbaum R, Kolks MAG, Kupfermann I, Weiss KR (1988) Structure and action of buccalin: a modulatory neuropeptide localized to an identified small cardioactive peptidecontaining cholinergic motor neuron of Aplysia californica. Proc Natl Acad Sci USA 85:6177-6181.

Cropper EC, Miller MW, Vilim FS, Tenenbaum R, Kupfermann I, Weiss KR (1990a) Buccalin is present in the cholinergic motor neuron B16 of Aplysia and it depresses accessory radula closer muscle contractions evoked by stimulation of B16. Brain Res 512:175-179.

Cropper EC, Kupfermann I, Weiss KR (1990b) Differential firing patterns of the peptide-containing cholinergic motor neurons B15 and B16 during feeding behavior in Aplysia. Brain Res 522:176-179.

Cropper EC, Vilim FS, Alevizos A, Tenenbaum R, Kolks MAG, Rosen SC, Kupfermann I, Weiss KR (1991) Structure, bioactivity, and cellular localization of myomodulin B: a novel Aplysia peptide. Peptides 12:683-690.

Greenberg MJ, Doble KE, Lesser W, Lee TD, Pennell NA, Morgan CG, Price DA (1997) Characterization of myomodulin-related peptides from the pulmonate snail Helix aspersa. Peptides 18:1099-106.

Hökfelt T (1991) Neuropeptides in perspective: the last ten years. Neuron $7: 867-879$.

Iversen LL (1995) Neuropeptides: promise unfulfilled? Trends Neurosci 18:49-50.

Kellett E, Perry SJ, Santama N, Worster BM, Benjamin PR, Burke JF (1996) Myomodulin gene of Lymnaea: structure, expression, and analysis of neuropeptides. J Neurosci 16:4949-4957.

Kupfermann I (1991) Functional studies of cotransmission. Physiol Rev 71:683-732.

Llinas R, Sugimori M, Silver RB (1992) Microdomains of high calcium concentration in a presynaptic terminal. Science 256:677-679.

Lloyd PE, Church PJ (1994) Cholinergic neuromuscular synapses in Aplysia have low endogenous acetylcholinesterase activity and a highaffinity uptake system for acetylcholine. J Neurosci 14:6722-6733.

Lloyd PE, Kupfermann I, Weiss KR (1988) Central peptidergic neurons regulate gut motility in Aplysia. J Neurophysiol 59:1613-1625.
Matteoli M, Haimann C, Torri-Tarelli F, Polak JM, Ceccarelli B, DeCamilli P (1988) Differential effect of a-latrotoxin on exocytosis from small synaptic vesicles and from large dense-core vesicles containing calcitonin gene-related peptide at the frog neuromuscular junction. Proc Natl Acad Sci USA 85:7366-7370.

Merighe A, Polak JM, Fumagalli G, Theodosis, DT (1989) Ultrastructural localization of neuropeptides and GABA in the rat dorsal horn: a comparison of different immunogold labeling techniques. J Histochem Cytochem 37:529-540.

Miller MW, Alevizos A, Cropper EC, Vilim FS, Karagogeos D, Kupfermann I, Weiss KR (1991) Localization of myomodulin-like immunoreactivity in the central nervous system and peripheral tissues of Aplysia californica. J Comp Neurol 314:627-644.

Miller MW, Alevizos A, Cropper EC, Kupfermann I, Weiss KR (1992) Distribution of buccalin-like immunoreactivity in the central nervous system and peripheral tissues of Aplysia. J Neurosci 320:182-185.

Miller MW, Beushausen S, Cropper EC, Eisinger K, Stamm S, Vilim FS, Vitek A, Zajc A, Kupfermann I, Brosius J, Weiss KR (1993a) The buccalin-related neuropeptides: isolation and characterization of an Aplysia: cDNA clone encoding a family of peptide cotransmitters. J Neurosci 13:3346-3357.

Miller MW, Beushausen S, Vitek A, Stamm S, Kupfermann I, Brosius J, Weiss KR (1993b) The myomodulin-related neuropeptides: Characterization of a gene encoding a family of peptide cotransmitters in Aplysia. J Neurosci 13:3358-3367.

Peng Y, Zucker RS (1993) Release of LHRH is linearly related to the time integral of presynaptic $\mathrm{Ca}+$ elevation above a threshold level in bullfrog sympathetic ganglia. Neuron 10:465-473.

Price DA, Lesser W, Lee TD, Doble KE, Greenberg MJ (1990) Seven FMRFamide-related and two SCP-related cardioactive peptides from Helix. J Exp Biol 154:421-437.

Reed W, Weiss KR, Lloyd PE, Kupfermann I, Chen M, Bailey CH (1988) Association of neuroactive peptides with the protein secretory pathway in identified neurons of Aplysia californica: immunolocalization of $\mathrm{SCPa}$ and $\mathrm{SCPb}$ to the contents of dense core vesicles and the trans face of the golgi apparatus. J Comp Neurol 272:358-369.

Verhage M, McMahon HT, Ghijsen WEJM, Boomsma F, Scholten G, Weigant VM, Nicholls DG (1991) Differential release of amino acids, neuropeptides, and catecholamines from isolated nerve terminals. Neuron 6:517-524.

Vilim FS, Cropper EC, Rosen SC, Tenenbaum R, Kupfermann I, Weiss KR (1994) Structure, localization and action of buccalin b - a bioactive peptide from Aplysia. Peptides 15:959-969.

Vilim FS, Price DA, Lesser W, Kupfermann I, Weiss KR (1996a) Costorage and corelease of modulatory peptide cotransmitters with partially antagonistic actions on the accessory radula closer muscle of Aplysia californica. J Neurosci 16:8092-8104.

Vilim FS, Cropper EC, Price DA, Kupfermann I, Weiss KR (1996b) Release of peptide cotransmitters in Aplysia: regulation and functional implications. J Neurosci 16:8105-8114.

Wang Y, Price DA, Sahley CL (1998) Identification and characterization of a myomodulin-like peptide in the leech. Peptides 19:487-493.

Weiss KR, Brezina V, Cropper EC, Hooper S, Miller MW, Probst WC, Vilim, FS, and Kupfermann, I (1992) Peptidergic co-transmission in Aplysia: functional implications for rhythmic behaviors. Experientia 48:456-463.

Whim MD, Lloyd PE (1994) Differential regulation of the release of the same peptide transmitters from individual identified motor neurons in culture. J Neurosci 14:4244-4251. 